\title{
Ueber das Verhalten von Protoplasma zu Neutralrot.
}

Von

\section{T. Takeuchi.}

Vor einiger Zeit hat J. LoEB ${ }^{1)}$ in Californien bei Studien über die Entwicklung des Seeigeleies unter Andern beobachtet, dass das lebendige Seeigelei sich leicht mit Neutralrot ${ }^{2)}$ färbt und diesen Farbstoff rasch wieder verliert mit dem Tode des Eies. Dieses Verhalten ist eine merkwürdige Ausnahme; denn mit gewöhnlichen Farbstoffen färbt sich das lebendige Protoplasma nicht, sondern nur das todte. Es war mir deshalb sehr interessant, das Verhalten einiger Algen und Infusorien $z \mathfrak{u}$ Neutralrot zu beobachten. Ich versuchte zuerst eine Auflösung von 1 Teil Neutralrot in 1000 Teilen Wasser, welches aus Glass destilliert war auf Spirogyren und beobachtete, dass der Farbstoff zwar rasch aufgenommen wurde, aber die Algen ebenso rasch dadurch getötet wurden; denn schon nach 30 Minuten konnte durch 10 prozentige Lösung von Rohrzucker keine Plasmolyse mehr erzielt werden, obwohl das Cytoplasma noch ganz an seiner ursprünglichen Stelle zu liegen schien. Nach Entfernung des meisten Farbstoffes mit Essigsäure konnte man deutlich erkennen, das der Kern und besonders der Nucleolus intensiv gefärbt waren.

1) Biochem. Zeitschr. 1906, Bd. 2, S. 43.

2) Die Formel des Neutralrots oder Toluylenrots ist:<smiles>Cc1cc2c3cn(c4ccc(N(C)C)cc34)c2cc1N</smiles> 
Bei meinem nächsten Versuche verwendete ich eine $0.1 \mathrm{p}$. mille und $0.01 \mathrm{p}$. mille Lösung und hier beobachtete ich, dass der Farbstoff sehr langsam in die Zelle aufgenommen wurde und dass nur solche Zellen sich stark färbten welche keine Plasmolyse in Zuckerlösung mehr gaben. Ferner wurde beobachtet, dass vorher mit Chloroform getötete Zellen den Farbstoff viel rascher aufnahmen als die lebenden Zellen. Ein weiterer Versuch mit Mougeotia verlief ganz gleich; nur war dabei zu bemerken, dass die kleinen Körnchen in diesen Zellen sehr rasch Farbstoff aufnahmen und zwar so lange die Zellen noch lebten. Bei Infusorien wurde beobachtet, dass sie im lebenden Zustand sich nicht färbten, sondern erst nach dem Tode.

Wir sehen also aus diesen Versuchen, dass das Protoplasma in Bezug auf diesen Farbstoff keine Ausnahme macht von der Regel und es müssen daher ganz besondere Umstände beim Seeigelei sein, welche ein anderes Verhalten des lebenden Protoplasmas bedingen. Vielleicht sind es gewisse Nebenprodukte, welche bei diesem Ei den Farbstoff aufnehmen so lange das Protoplasma noch lebten.

Agricultur-chemisches Institut der Universität, Tokyo. 